\title{
TRES POETAS EN BUSCA DE AMÉRICA: ALBERTI, GUILLÉN Y HUGHES
}

Barbara Dale May

Un nuevo idealismo fundado en principios humanistas y hasta utópicos corría por el mundo entero hacia mediados del siglo pasado. Tal vez representara la expresión heroica de ideales ya nacidos mucho antes pero callados por la intolerancia y el miedo; tal vez fuera una simple reacción inevitable contra la realidad opresiva del momento histórico mundial. De todos modos, la idea encontró su palabra y se oía la voz popular del Romanticismo.

Mientras muchos pueblos coloniales de América del Sur habían logrado la independencia política de Europa, en la otra América se sentía la discordia de un país libertado por la fuerza revolucionaria e, irónicamente, plagado con su propia institución de esclavitud. Pocos años antes de la Guerra Civil en Norte América, un poeta neoyorquino había advertido la crisis inminente de su país al mismo tiempo que soñaba con una nueva América:

Come, I will make the continent indissoluble,

I will make the most splendid race the sun ever shone upon,

I will make divine magnetic lands,

With the life-long love of comrades, With the life-long love of comrades.

I will plant companioship thick as trees along all the rivers of America, and along the shores of the great lakes, and all over prairies,

I will make inseparable cities with their arms about each other's necks,

By the love of comrades,

By the manly love of comrades. ${ }^{1}$

Así enunciaba Walt Whitman su sueño de América, no sospechando en aquel entonces que le iban a seguir otros poetas-visionarios, amenazados por una crisis paralela y en busca de aquella nación utópica. Tampoco podía saber que serían de varios países ni que su alianza representaría una intersección de razas y culturas.

En 1936 la atención del mundo no se fijó en las Américas sino en otro país que, como la América de Whitman, se acercaba a una guerra civil. España, y más específicamente, la capital republicana de Madrid, fue el centro de acontecimientos político-históricos de gran trascendencia mundial. Por lo que se refiere al presente estudio, se puede decir que la España de los años '30 proporcionó el eje para la relación biográfica-literaria 
entre los grandes poetas Rafael Alberti, Nicolás Guillén y Langston Hughes. Además, les proveyó del ímpetu necesario para buscar consuelo en una nueva América utópica.

El sueño de América en los tres es más que una simple búsqueda política, porque expone la filosofía personal de cada poeta, edificada tanto por la experiencia única del individuo como por el momento histórico en que vivía. El estudio de esta búsqueda, además de demonstrar la postura de cada poeta ante el desequilibrio de su época, puede explicar su actitud hacia la poesía política y su papel funcional. E, indudablemente, puede iluminar la atmósfera de la época misma.

Por medio de esta búsqueda del país ideal, cada poeta parece menos um portavoz de su propio pueblo y más bien el representante de una generación y un pueblo universales. Además se observa que el sueño de América es la manifestación política de una actitud existencial reflejada en la poesía comprometida de los tres.

Sin duda, son muchas las desemejanzas biográficas de estos tres poetas. Se destacan primero las grandes diferencias culturales y raciales: Alberti es andaluz, de descendencia italiana; Guillén, cubano, de padres mestizos; Hughes, norteamericano, de origen negro. Mas estas disparidades biográficas no justifican la falta de atención crítica hacia el desarrollo de la relación entre los tres y la influencia de ella sobre su producción literaria. Existen varios estudios excelentes sobre la vida y obra de cada poeta. Sin embargo, hay un vacío crítico inexcusable que se refiera a esta relación importantísima. Por ejemplo, la crítica sobre Alberti abunda en detalles que tratan su participación durante la Guerra Civil, específicamente su actividad como secretario de la Alianza de Intelectuales Antifascistas y su intervención en el II Congreso Internacional de Escritores. Aunque casi todos los críticos están de acuerdo en que es imprescindible estudiar el aspecto universal de la obra de Alberti, observando su contacto con otros poetas fuera de la llamada Generación del '27, casi todos han hecho caso omiso de su amistad con dos delegados extranjeros al II Congreso, amistad que vincula continentes, razas y culturas.

No es decir que los críticos de Guillén y Hughes hayan considerado el asunto de una manera más profunda. No obstante, en el segundo tomo de su excelente obra Nicolás Guillén: notas para un estudio biográfico-critico, Angel Augier considera de una perspectiva bien circunspecta las actividades del poeta cubano entre los años 1934 y 1948, al mencionar la visita de Alberti y su esposa María Teresa a Cuba en 1934 y los viajes de Guillén a México, los EE.UU. y España en 1937. Augier, más que cualquier otro biógrafo-crítico se da cuenta de las reuniones de Guillén con Alberti y Hughes, y, a lo menos, alude a ciertos puntos de contacto literarios. ${ }^{2}$

De una manera parecida, si bien menos completa, los biógrafos y críticos de Langston Hughes han tratado su contacto con Alberti y Guillén durante la guerra civil de España. Entre los que han estudiado la vida y obra de Hughes, se destacan Donald C. Dickinson y James A. Emanuel, quienes, en sus trabajos respectivos consideran su poesía y prosa revolucionarias. ${ }^{3}$ Ambos explican la fuente biográfica de su compromiso político, un empeño inspirado por la experiencia temprana del negro joven en América. Sin embargo, aunque ambos críticos citan el contacto de Hughes con tales poetas como Jacques Roumain y Nicolás Guillén y el gran interés de Hughes por traducir la poesía extranjera, ninguno de los dos examina muy detenidamente la estancia de Hughes en España durante la guerra ni, por supuesto, la importancia de su relación entablada allí con Guillén y Alberti. 
A pesar de las mencionadas desemejanzas superficiales que existen entre Alberti, Hughes y Guillén, hay coincidencias biográficas y correspondencias literarias que exigen un estudio mucho más amplio que el presente. Algunas fuentes ricas para investigaciones biográficas y críticas de estos coétanos ${ }^{4}$ serían el momento y ambiente históricos de su nacimiento y juventud; la orfandad real o figurada en los tres; ${ }^{5}$ el desengaño de todos con la religión organizada; y, por supuesto, la actividad y el compromiso políticos de ellos dentro y fuera de sus propios países.

La conciencia social y, más tarde, el compromiso político de cada poeta fueron el resultado de la enajenación social que experimentaron desde jóvenes. Aquí se estudiará la relación intima entre la enajenación social (o sea, la realidad) y la unidad fraterna espiritual (el sueño) que son elementos representados por medio de los símbolos de la España de los años '30 y la América del porvenir. Aunque la enajenación fue inspirada por diversos episodios personales en la vida de cada individuo, se puede ver que existe en planos paralelos y que es la enejenación misma lo que les lleva a soñar con la utopía y comprometerse a ciertos ideales del socialismo. Las raíces de tal enajenación en Alberti se basan primero en la situación económica de su familia durante su niñez. Habiendo perdido su riqueza y poder, su familia estaba en un período de declive social, cuyo resultado fue en el caso de Rafael el ser externo en el colegio de San Luis Gonzaga. Cuando describe el desigual tratamiento que recibian los externos y los internos a manos de sus maestros, está hablando de su primer encuentro con la división de clases que era patente. Además expresa la importancia que esa experiencia tuvo en su futura actitud política:

Estas grandes y pequeñas diferencias nos dolían muchísimo, barreando en nosotros, según íbamos creciendo en sensibilidad y razón, un odio, que hoy sólo encuentro comparable a ese que los obreros sienten por sus patronos, es decir, un odio de clase. ${ }^{6}$

Es obvia la interrelación de clase y el desengaño con la religión organizada aquí representada por los jesuitas. También es evidente la unidad fraterna con los otros externos que sintió el joven desengañado.

La enajenación de Guillén comenzó a una edad temprana también. Mientras su padre fue periodista y senador, Nicolás y su hermano podían trabajar en el taller familiar, pero a la muerte del padre, tuvieron que buscar trabajo en otro, para ganar la vida para toda la familia. Siendo huérfano, mestizo, pobre y de una familia castigada por el gobierno, Guillén conoció desde muy joven el prejuicio racial y económico en que se basa su enajenación social:

Así andamos por la ciudad, como perros abandonados en medio de una tempestad.

El sol nos tuesta en su candela, pero por la noche la luna de un escupitajo nos hiela. ${ }^{7}$ 
no tengo donde vivir, ni mujer a quien querer; todos los perros me ladran: y nadie me dice usted. ${ }^{8}$

La juventud de Langston Hughes lleva la misma estampa de enajenación. De niño, vivió por poco tiempo en varios estados de los EE.UU., Missouri, Illinois, Ohio, y otros. Mientras estuvo en Topeka, Kansas, fue el único alumno negro de su escuela y sufrió las afrentas verbales y los abusos físicos de los otros estudiantes. Afortunadamente, no todas sus experiencias con los blancos fueron negativas y pudo disfrutar el sentimiento fraterno que iba a cruzar fronteras raciales. De todos modos, no se olvidó de su primer encuentro con el racismo y se refirió a su desengaño con la llamada democracia americana en el II Congreso Internacional de Escritores en 1937:

I come from a land whose democracy from the very beginning has been tainted with race prejudice born of slavery and whose richness has been poured through the narrow channels of greed into the hands of the few. I come to the Second International Writers Congress representing my country, America, but most especially the Negro peoples of America, and the poor peoples of America - because I am both a Negro and poor. ${ }^{9}$

Dado que Hughes, Alberti y Guillén experimentaron los mismos sentimientos de frustración con la realidad socio-política de sus propios países, no es sorprendente que buscaran otra realidad más agradable que la actual. Tampoco es inesperado que se comprometieran desde jóvenes al movimiento popular del socialismo y específicamente a los ideales humanistas de aquella fraternidad mundial.

Fue, tal vez, aquel idealismo que le llevó al poeta cubano y al norteamericano a España durante la guerra civil. Ambos fueron como periodistas, Guillén representando la revista Mediodi $^{10}$ y Hughes The Baltimore Afro-American. Aunque la reunión de los tres en Madrid durante la guerra significa el núcleo de su amistad, no se puede decir que fuera el primer encuentro de estos poetas. Hay que recordar que Hughes había conocido a Guillén por vez primera en Cuba en $1930{ }^{11}$ que los Alberti habían viajado a Cuba en 1935 para dar conferencias y recitales; y que todos volvieron a reunirse dos años después para el II Congreso Internacional de Escritores para la Defensa de la Cultura.

La guerra de España fue para todos ellos un episodio crítico, porque eran no sólo poetas-periodistas sino también participantes en la lucha contra el fascismo. En "Hero-International Brigade" Hughes escribe:

I've given what I wished

And what I had to give

That others live.

And when the bullets

Cut my heart away,

And the blood

Gushed to my throat

I wondered if it were blood

Gushing there.

Or a red flame?

Or just my death

Turned into life? 


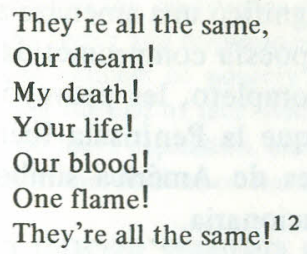

El mismo sentimiento fraterno lo expresa Guillén en su poesía, inspirada en la guerra de España. Así que el conflicto de los republicanos y los fascistas no se vio sólo como una guerra civil corriente, sino como una batalla simbólica entre clases, cuyo protagonista para Alberti, Hughes y Guillén fue el obrero universal, el soldado proletario. En unos versos dedicados a España de su obra España, poema en cuatro angustias y una esperanza, Guillén expresa su simpatía por la causa republicana y también indica las raíces personales de su interés humanista:

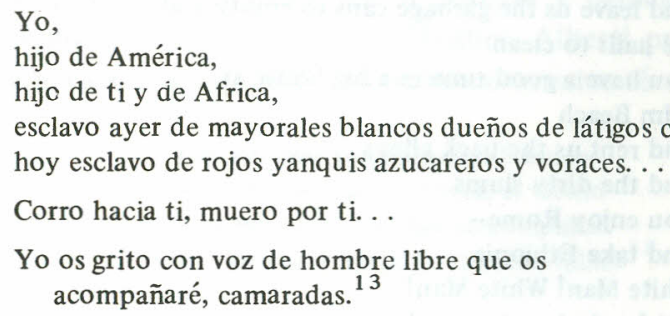

Además de expresar la simpatía por sus camaradas españoles, Guillén articula la fraternidad revolucionaria del socialismo: " ${ }_{\mathrm{i}} \mathrm{Y}$ la canción alegre flotará como una nube/sobre la roja lejanía!"14

Dado que los tres se identificaban tanto con el pueblo y la gente común y hasta se consideraban "poetas de la calle", no es sorprendente que emplearan una voz popular en su poesía para comunicarse con la gente y para animarla en su lucha. Una correspondencia de la técnica y la actitud de estos poetas que no está muy ajena del presente estudio es la expresión de lo popular a través de sus versos. Mientras Alberti perfeccionaba sus coplas, canciones y baladas, siendo todas ejemplos vivos de la métrica popular y tradicional, Guillén se expresaba a través del son, una forma popular típicamente cubana. De una manera parecida, Langston Hughes experimentaba con los ritmos de Jazz y Blues características de la música negra estadounidense. El mismo sentimiento fraterno humanista movió a Alberti a crear su revista revolucionaria El mono azul y a Guillén a establecer Mediodia y, tal vez, resultó en la producción de Dynamo, una revista semejante concebida por Hughes. Aquel sentimiento de hermandad popular les animó en sus actividades políticas y poéticas por casi toda la vida.

Debido a su gran idealismo y la manifestación política de él en términos socialistas, los tres sintieron personalmente la caída de la República en 1939. La derrota de aquella España heroica representó la pérdida de un sueño para ellos. Para Alberti, la derrota de la República iba a redundar en grandes consecuencias personales, específicamente, largos años de destierro y frustración. La figura de España le iba a perseguir por toda su vida e iba a imponer su estampa indeleble en su obra literaria. Para todos, Guillén, Hughes y 
Alberti, la caída de España lealista significó una amenaza a su ideal político y también un desafío para la continuación de su poesía comprometida y revolucionaria. La figura de España, vencida y derrotada por completo, les proveyó una realidad a que se iban a oponer el sueño utópico. Mientras que la Península Ibérica representaba el triunfo del absolutismo fascista, los continentes de América simbolizaban una nueva resistencia socialista, una nueva esperanza revolucionaria.

El sueño de América para Hughes, Alberti y Guillén se basa en la unidad fraterna de las razas. Sin embargo, hay que mencionar que Guillén y Hughes tuvieron que pasar por un período en que su obra se caracterizó por un racismo negro, en que expresaron el orgullo de sus orígenes y la ira y el odio del negro hacia su explotador blanco:

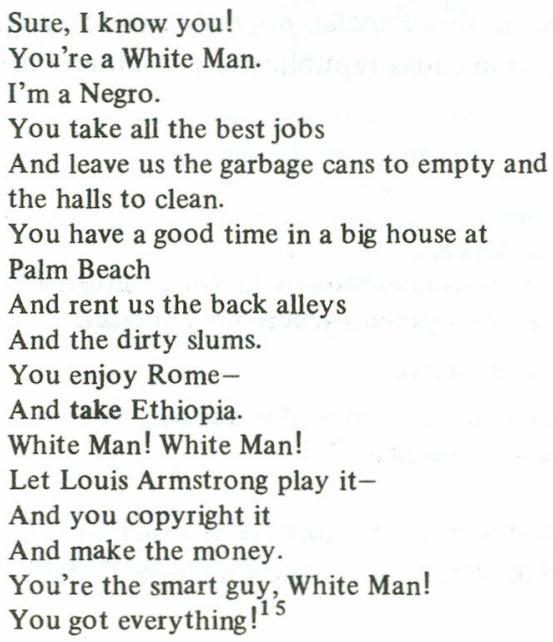

Afortunadamente, ambos pasaron rápidamente por aquella fase de su obra y reconocieron la necesidad de una unión mundial que no diera ninguna importancia a la diferencia racial. En un ensayo que apareció en Hoy, Guillén observó:

¿Qué raza podíamos honrar, pues, este 12 de octubre, que no fuera la raza universal, cuyo desarrollo depende de la pigmentación de la piel, sino de circunstancias propicias o adversas, emanadas de los medios económicos puestos a su alcance y los cuales determinan su estancamiento o su progreso? ....

....El 12 de octubre, es decir, el descubrimiento de América, es patrimonio de la cultura humana, y ésta nunca ha sido ni será privilegio de un puñado de hombres, por muy racistas que sean. ${ }^{16}$

En su discurso ante el II Congreso Internacional de Escritores, Langston Hughes articuló la misma actitud anti-racista que formó la base de su compromiso político:

Just as in America they (the Fascists) tell the whites that Ngroes are dangerous brutes and rapists, so in Germany they lie about the Jews and in Italy they cast their verbal spit upon the Ethiopians.

....the reactionary and Fascist forces of the world know that writers like Anand and myself, leaders like Herndon and poets like Guillén and Roumain represent the great longing that is in the hearts of the darker peoples of the world to reach out their hands 
in friendship and brotherhood to all the white races of the earth. The Fascists know that we long to be rid of hatred and terror and oppression, to be rid of conquering and being conquered, to be rid of all the ugliness of poverty and imperialism that eat away the heart of life today. We represent the end of race. Ant the Fascists know that when there is no more race there will be no more capitalism, and no more war, and no more money for the munition makers, because the workers of the world will have triumphed. ${ }^{17}$

De esta manera se puede ver la relación enredada en que se funden y se coinciden las actitudes socialistas y anti-racistas de estos tres poetas. Así que, mientras los dos negros simpatizaron con la causa anti-fascista de la República española, el español les compadeció en su lucha contra el imperialismo racista.

Cuatro años antes de la derrota de la República, después de dar unas conferencias y recitales en Nueva York, Alberti escribió "Trece bandas y cuarenta y ocho estrellas", una serie de poemas en torno de América. Sin duda alguna, el poeta sentía repugnancia por la explotación económica de las naciones latinoamericanas y así señaló a los EE.UU. como el mayor enemigo político motivado por la avaricia y caracterizado por la expansión agresiva. En un poema dedicado a Langston Hughes, Alberti presenta la culpabilidad del capitalismo norteamericano al referirse a su bandera en estos términos:

Las estrellas verdad se confabulen con tu robado mar, la tierra, el viento contra esas trece bandas corrompidas y esa Company Bank de estrellas falsas. ${ }^{18}$

Y pide que el sueño de América revolucionaria sea articulado por las víctimas de aquella explotación:

Suene este canto, no como el vencido letargo de las quenas moribundas, sino como una voz que estalle uniendo la dispersa conciencia de las olas.

Tu venidera órbita asegures con la expulsión total de tu presente. Aire libre, mar libre, tierra libre. Yo también canto América futura. ${ }^{19}$

Es interesante que el título de este poema, "Yo también canto a América" es el del escrito con anterioridad por Langston Hughes en que condena la desigualdad racista en los EE.UU. . En ese poema, Hughes pide una nueva era de igualdad y unidad:

I, too, sing America.

I am the darker brother.

They send me to eat in the kitchen

When company comes,

But I laugh,

And eat well,

And grow strong.

Tomorrow,

I'll be at the table

When company comes. 
Nobody'll dare

Say to me,

'Eat in the kitchen,'

Then.

Besides,

They'll see how beautiful I am

And be ashamed-

I, too, am America. ${ }^{20}$

Por supuesto, los versos de ambos poetas traen a la memoria el recuerdo del poema de Whitman, "I Hear America Singing" en que se refería a la unión fraterna del pueblo americano.

Tal vez lo más sorprendente de la relación Alberti-Hughes-Guillén se encuentra en el hecho de que podían compartir un ideal político pese a las grandes diferencias entre sus orígenes y formación. Se puede observar que aún las perspectivas de cada poeta se distinguen entre sí. Guillén podía ver la agresión norteamericana desde el punto de vista de uno amenazado directamente por la explotación extranjera, o sea, la política estadounidense. Aunque siente cierta tensión dentro de $\mathrm{Cuba}^{21}$, tiende a aislar al enemigo y definirlo como "el vecino", "el otro", "el intruso":

Rojo desciende de su avión

míster Smith, un cuadrumano

de la selva de Guasintón.

Hay cóctel en la legación.

Un yanqui allí, látigo en mano. ${ }^{22}$

De este modo Guillén desempeña el papel de poeta comprometido, testigo y portavoz popular, un cubano contra la proximidad malévola del enemigo extranjero.

En cambio, Rafael Alberti, no siendo latinoamericano, sino un extranjero interesado, percibe tal peligro desde un punto de vista más distante. No siendo amenazado directamente por la política estadounidense, puede lograr un examen de la situación desde fuera, aunque sea con gran simpatía y compasión hacia los países hispánicos de América. Comparte con Guillén la ira irreprensible contra cualquier clase de explotación y la expresa en el poema "New York":
Mas aún por América arde el pulso
de agónicas naciones que me gritan
con mi mismo lenguaje entre la niebla, tramando tu mortal sacudimiento.
Así un día tus trece horizontales y tus cuarenta y ocho estrellas blancas verán desvanecerse en una justa libertadora llama de petróleo. ${ }^{23}$

Entre los poetas considerados en este estudio se destaca Langston Hughes como el más íntimamente enredado en la ira y la esperanza de una nueva América. Siendo estadounidense y negro, observa la doble amenaza de los EE.UU.: la hacia el mundo 
externo, o sea, hacia los países latinoamericanos, y la del país hacia sí mismo, hacia su propio pueblo. Así que el sueño de América en Hughes no se limita a la América Latina, sino se extiende a la otra América que se presenta simultáneamente como víctima y opresor. En el poema "Freedom's Plow" Hughes reconoce la universalidad de su sueño de América:

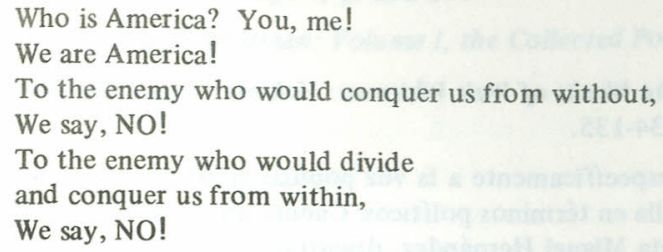

A long time ago,

An enslaved people heading toward freedom

Made up a song:

Keep your hand on the plow! Hold on!

That plow plowed a new furrow

Across the field of history.

Into that furrow the freedom seed was dropped.

From that seed a tree grew, is growing, will ever grow.

That tree is for everybody,

For all America, for all the world.

May its branches spread and its shelter grow

Until all races and all peoples know its shade. ${ }^{24}$

A pesar de las disparidades que existen entre las perspectivas de Alberti, Guillén y Hughes, el sueño de una América ideal refleja la búsqueda humanista de cada poeta. Aquella América lejana se establece en principios nobles si bien utópicos e intangibles. La perfección de una democracia social sigue siendo una ilusión para los tres así como lo había sido para su abuelo espiritual, Walt Whitman:

Leave to the singers of hitherto, give them the trailing past,

But what remains remains for singers for you - wars to come are for you,

(Lo, how the wars of the past have duly inured to you, and the wars of the present also inure;)

Then turn, and be not alarm'd O Libertad - turn your undyind face,

To where the future, greater than all the past,

Is swiftly, surely preparing for vou. ${ }^{25}$

Department of Romance Languages

University of Oregon

Eugene, Oregon

USA 


\section{NOTAS}

${ }^{1}$ Walt Whitman, The Works of Walt Whitman: Volume I, the Collected Poetry (New York: Funk and Wagnalls, 1968), p. 134-135.

${ }^{2}$ Augier se dirige específicamente a la voz popular empleada por Guillén y Hughes en su poesía y el papel funcional de ella en términos políticos. Cuenta que cierto día en 1937 mientras almorzaban Guillén, Hughes y el poeta Miguel Hernández, discutían el tema de la expresión revolucionaria en el verso. Véase el segundo tomo de Nicolás Guillén: notas para un estudio biográfico-critico (La Habana: Universidad Central de las Villas, 1964), p. 81-82.

${ }^{3}$ Véase Donald C. Dickinson, A Bio-bibliography of Langston Hughes (Hamden, Connectituc: Archon Books, 1972) y James A. Emanuel, Langston Hughes (New York: Twayne Publishers, 1967).

${ }^{4}$ Los tres nacieron en 1902.

${ }^{5}$ Me refiero especialmente a la relación entre los poetas y sus padres. El de Alberti, por ejemplo, era una figura distante de su niñez, un padre pasajero debido a los negocios que le llevaban lejos de su familia. La relación entre Hughes y su padre era aún más difícil. Después de la separación y el divorcio de sus padres, Hughes vivió con su abuela, para volver luego a vivir con su madre y padrastro. Aunque pasó un año en México con su padre, nunca disfrutaba la intimidad filial. En el caso de Guillén, se puede decir que el desarrollo de una relación profunda entre padre e hijo fue impedido trágicamente por el asesinato de aquél, a manos de tropas gubernamentales en 1917. Aunque Guillén escribió muchos versos en homenaje a su padre (véase "Canción filial" y "Elegía camagüeyana"), la figura paterna es más bien la de un mártir idealizado y así distante, que la de un ser verdadero.

${ }^{6}$ Rafael Alberti, La arboleda perdida, Libro I y II de memorias (Buenos Aires: Compañía General Fabril Editora, 1959), p. 37.

${ }^{7}$ Nicolás Guillén, Sóngoro cosongo (Buenos Aires: Losada, 1952), p. 82.

${ }^{8}$ Ibid., p. 93.

9 Langston Hughes, Good Morning, Revolution (New York: Lawrence Hill and Co., 1973), p. 97.

${ }^{10}$ Fue una revista mensual fundada en 1936, cuyo comité editorial se componía de varios marxistas cubanos, incluso Juan Marinello y Guillén mismo.

11 Guillén describe sus impresiones de Hughes en el Diario de la Mañana, en la página "Ideales de una raza", en un artículo titulado "Conversación con Langston Hughes" del 9 de marzo, 1930.

12 Hughes, Goode Morning, Revolution, p. 114.

13 Guillén, Sóngoro cosongo, p. 111-112.

14 Ibid., p. 115.

15 Hughes, Good Morning, Revolution, p. 5.

${ }^{16}$ Nicolás Guillén, Prosa de prisa (La Haban: iversidad Central de las Villas, 1962), p. 307-308.

${ }^{17}$ Hughes, Good Morning, Revolution, p. 98-99.

18 Alberti, Poesías completas (Buenos Aires: Losada, 1961), p. 399.

19 Ibid., p. 400. 
20 Hughes, Selected Poems of Langston Hughes (New York: Knopf, 1968), p. 275.

21 Véase El son entero, "Mi patria es dulce por fuera". (Buenos Aires: Losada, 1952), p. 52.

22 Guillén, La paloma de vuelo popular (Buenos Aires: Losada, 1958), p. 23.

23 Alberti, Poesías completas, p. 160.

${ }^{24}$ Hughes, Selected Poems of Langston Hughes, p. 296-297.

25 Walt Whitman, The Works of Walt Whitman: Volume I, the Collected Poetry, p. 297. 